\title{
Middle East Respiratory Syndrome coronavirus - two years into the epidemic
}

M Sprenger ${ }^{1}$, D Coulombier (denis.coulombier@ecdc.europa.eu)

1. European Centre for Disease Prevention and Control (ECDC), Stockholm, Sweden

Citation style for this article:

Sprenger M, Coulombier D. Middle East Respiratory Syndrome coronavirus - two years into the epidemic . Euro Surveill. 2014;19(16):pii=20783. Available online: http://www.eurosurveillance.org/ViewArticle.aspx?Articleld=20783

Article submitted on 24 April 2014 / published on 24 April 2014

Two years ago, on 23 April 2012, media reported a cluster of severe respiratory infection in a hospital in Jordan [1]. Only several months later did it become evident that this was the first known occurrence of the new Middle East Respiratory Syndrome coronavirus (MERS-CoV) that since then continues to puzzle scientists and public health experts alike.

As of 23 April 2014, 345 people have been reported infected, and of those 107 have died [2]. Most cases occurred in Saudi Arabia (SA) and to a lesser extent in the United Arab Emirates (UAE), still further 11 countries in Europe, Asia and North Africa have reported cases linked to the Arabian peninsula. Few clusters and cases were noted in the second half of 2012, and the epidemic has been stable at low levels in 2013, with about 15 cases notified monthly (Figure). This has changed dramatically over the past weeks when we faced an unprecedented increase in cases and community transmission as well as transmission in hospital settings.

In the past weeks, MERS-CoV cases imported to Jordan, Malaysia and the Philippines, have reminded us of the risk of seeing cases among expatriate residents in the Arabian Peninsula visiting their home countries or among travellers returning from SA. In this issue of Eurosurveillance, Tsiodras et al. report about the public health response to a MERS-CoV infection in a Greek national residing in SA who was diagnosed in Greece upon returning from SA [3]. The patient initially presented with fever and diarrhoea, possibly indicating

\section{FIGURE*}

Distribution of Middle East Respiratory Syndrome coronavirus cases by month of disease onset, February 2012-23 April 2014 $(n=345)$

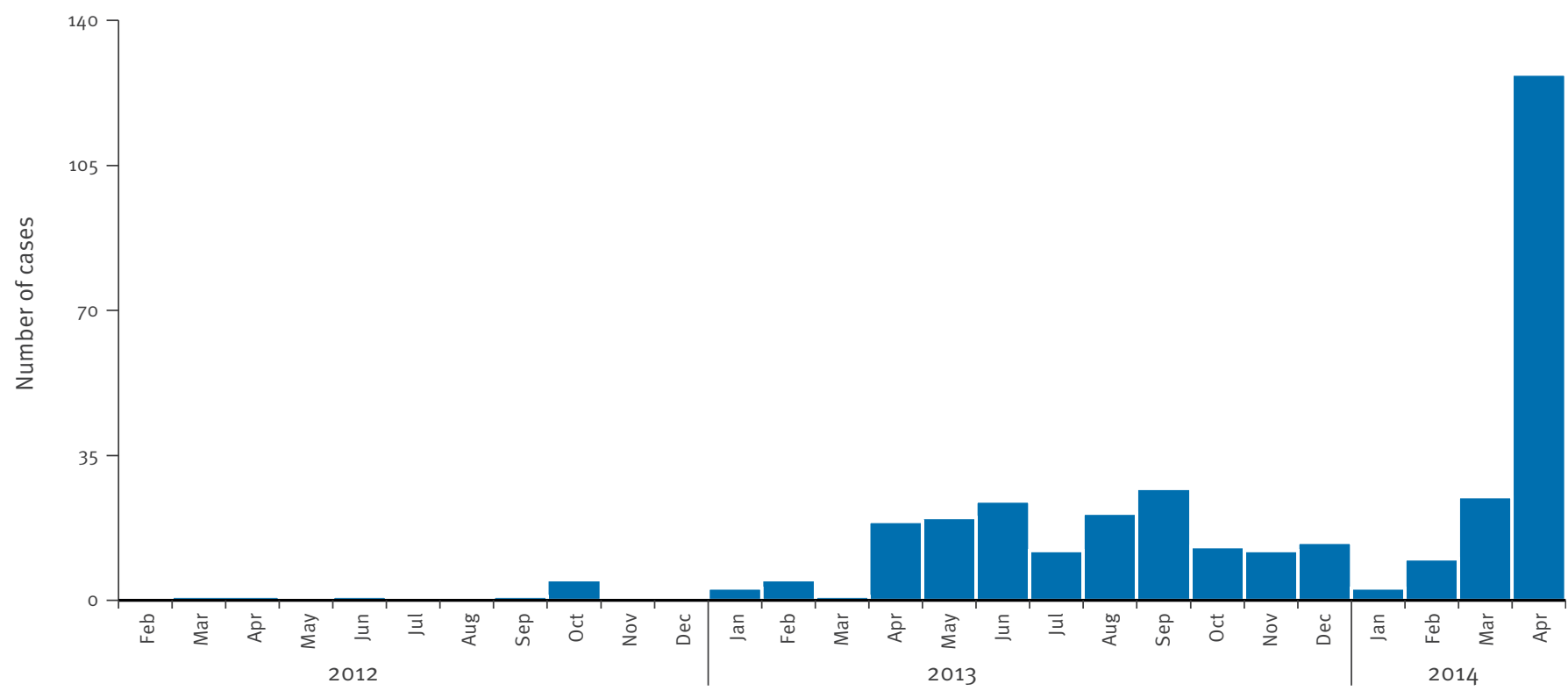


that the presentation of cases at early onset of the disease may not include prominent respiratory symptoms; this was already reported in a French case-patient with immunosuppressive condition in 2013 [4]. The World Health Organization (WHO) MERS-CoV Research Group reviewed 161 patients in November 2013, and indicated the French patient as the only one admitted for fever and diarrhoea in without initial respiratory symptoms. The group mentioned however, that at least one-third of patients also had gastrointestinal symptoms, such as vomiting and diarrhoea [5].

A second paper in this issue by Nowotny and Kolodziejek provides further evidence that the MERS-CoV is likely a zoonosis with camels playing a role as a reservoir for the virus as well as a possible source for transmission to humans, potentially through the respiratory route [6]. Still other transmission routes, e.g. foodborne, or a combination of routes cannot be excluded according to van Doremalen et al. [7].

In the past, emerging zoonoses have been triggered by changes in the interface between humans and animals. An example is the Q-fever outbreak in the Netherlands in 2009, where intensive goat farming in the vicinity of populated areas resulted in widespread transmission of the disease within the community [8]. Progressive changes have taken place in the farming of camels in SA in recent years, with a large increase in camel population and camel farms, in the proximity of the cities. While a Washington post editorial last week [9], pointed-out that 'after all, camels are not sitting in hospital waiting rooms' to support the fact that the recent hospital clusters in SA are likely to result from failure of the infection control procedures, camels are becoming more 'urbanised', as periurban camel farming is developing in SA [10].

The change in the epidemiology of MERS-CoV over the past weeks is of concern as stated in a facebook post by WHO's Eastern Mediterranean Regional Office on 23 April 2014 [11]. Interestingly, over the past two years, voices on social media have been increasingly important for reports about the MERS-CoV situation as they have kept the topic high on the agenda of by raising pertinent questions, curating content on blogs, and reporting on cases in near-real time via Twitter. We have seen the MERS CoV debate on Twitter engage bloggers and journalists along with public health organisations, epidemiologists and doctors alike, often resulting in faster reporting and better understanding of the situation. This debate relates to a new phenomenon called 'crowd epidemic intelligence' [12] and is particularly important given the many unknowns about the MERS epidemic.

Recent MERS-CoV cases comprise a significant proportion of healthcare workers and asymptomatic cases or cases presenting with mild symptoms. While this could partly result from a more aggressive screening of contacts in the context of two hospital clusters, it is unlikely to fully account for the observed increase as community-acquired cases have increased in parallel as well [2]. The increase of community-acquired reported cases noted since March this year may correspond to a seasonal factor in community-based transmission, potentially related to exposure to camels. It mimics the increase noted in April 2013 and the first occurrence observed in March 2012. Nowotny and Kolodziejek describe the high viral load in young camels. It is interesting to note that the possible seasonal increase of human MERS-CoV cases corresponds to the end of the calving season for camels in Saudi Arabia. [13] This temporal correlation has still to be explored.

Secondary person-to-person transmission in close family as well as in healthcare settings has occurred in the past and WHO issued recommendations for infection control measures for handling cases of MERS-CoV [14]. Yet it is unclear if the recent hospital clusters in $\mathrm{SA}$ and $\mathrm{UAE}$, resulted from a failure to adhere to these recommendations, or from the failure of these measures themselves!

Previous publications in Eurosurveillance already in September 2012, September and December 2013 raised questions and called for collaborative international public health efforts to mitigate and possibly contain the MERS-CoV outbreak [15-17]. Still, two years in the epidemic, many of the essential epidemiological parameters remain unknown, e.g. the source, the reservoir and the mode of transmission for primary cases. The role of camels in the emergence and transmission of the disease is further unexplained, even though the evidence for their implication is growing from veterinary and virology studies.

MERS-CoV infections present with a high case-fatality ratio, multiple transmission routes are suspected, cases are reported among healthcare workers, multiple disease foci are affecting SA, and cases have been exported. All these facts are criteria for considering declaring a public health event of international concern listed in annex II of the WHO international health regulations [18]. Two years and 345 cases after the start of this epidemic, we remain with many unanswered questions and lack serological studies and sequences from human cases.

Currently, SA bears the main burden of managing the MERS-CoV epidemic and lately also the UAE. So far, cases detected outside the Arabian Peninsula have not resulted in sustained onward transmission. However, the recent rapid change in the epidemiological pattern of the disease should call for a change of approach to ensure a rapid understanding of the determinants of this emerging epidemic and its effective control, which will require a joint intervention from veterinary as well as human health authorities worldwide. 


\section{* Authors' correction:}

On request of the authors, in the Figure the title was updated and a footnote added. This correction was made on 25 April 2014 .

\section{References}

1. Zarqa hospital staff 'cured' after disease outbreak, The Jordan Times, 21 Aprilk 2012. Available from: http://jordantimes.com/ zarqa-hospital-staff-cured-after-disease-outbreak

2. Flutrackers, 2012-2014 Case List of MoH/WHO Novel Coronavirus nCoV Announced Cases. Available from: http:// www.flutrackers.com/forum/showthread.php? $t=205075$

3. Tsiodras S, Baka A, Mentis A, Iliopoulos D, Dedoukou X, Papamavrou G, et al. A case of imported Middle East Respiratory Syndrome coronavirus infection and public health response, Greece, April 2014. Euro Surveill. 2014;19(15): $\mathrm{pii}=20782$

4. Mailles A, Blanckaert K, Chaud P, van der Werf S, Lina B, Caro V, et al. First cases of Middle East Respiratory Syndrome Coronavirus (MERS-CoV) infections in France, investigations and implications for the prevention of humanto-human transmission, France, May 2013. Euro Surveill. 2013;18(24): $\mathrm{pii}=20502$.

5. The WHO MERS-CoV Research Group, State of Knowledge and Data Gaps of Middle East Respiratory Syndrome Coronavirus (MERS-CoV) in Humans, PLoS Curr. 2013 November 12; 5: ecurrents.outbreaks.obf719e352e7478f8ad85fa30127ddb8. Available from: http://www.ncbi.nlm.nih.gov/pmc/articles/ PMC3828229/

6. Nowotny N, Kolodziejek J. Middle East respiratory syndrome coronavirus (MERS-CoV) in dromedary camels, Oman, 2013. Euro Surveill. 2014;19(15):pii=20781.

7. van Doremalen N, Bushmaker T, Karesh WB, Munster VI. Stability of Middle East respiratory syndrome coronavirus in milk [letter]. Emerg Infect Dis. 2014;20(7). [Internet]. Forthcoming. http://dx.doi.org/10.3201/eid2007.140500.

8. Dijkstra F, van der Hoek W, Wijers N, Schimmer B, Rietveld A, Wijkmans CJ, et al. The 2007-2010 Q fever epidemic in The Netherlands: characteristics of notified acute $Q$ fever patients and the association with dairy goat farming. Immunol Med Microbiol. 2012 Feb;64(1):3-12. http://dx.doi. org/10.1111/j.1574-695X.2011.00876.x

9. New killer virus should be fought with the help of Saudi honesty. Washington post editorial board, 19 April, http:// www.washingtonpost.com/opinions/new-killer-virus-shouldbe-fought-with-saudi-honesty/2014/04/18/5f5aboc2-c5b411e3-bf7a-be01agb69cf1_story.htm

10. H. R. Abdallah1 and Bernard Faye, Typology of camel farming system in Saudi Arabia, Emir. J. Food Agric. 2013. 25 (4): 250260, http://ejfa.info/index.php/ejfa/article/view/15491/8257

11. World Health Organization (Eastern Mediterranean Regional Office), Facebook posting, 24 April 2014 available from https://www.facebook.com/WHOEMRO/ posts/650401965008625

12. Diaz-Aviles E, Stewart A, Velasco E, Denecke K, Nejdl W. Epidemic Intelligence for the Crowd, by the Crowd. Proceedings of the Sixth International AAAI Conference on Weblogs and Social Media. 2012. Available from: http://www.aaai.org/ocs/ index.php/ICWSM/ICWSM12/paper/viewFile/4594/5687

13. Almutairi SE1, Boujenane I, Musaad A, Awad-Acharari F. Non-genetic factors influencing reproductive traits and calving weight in Saudi camels. Trop Anim Health Prod. 2010;42(6):1087-92. Available from: http://www.ncbi. nlm.nih.gov/pubmed/20195755 http://dx.doi.org/10.1007/ S11250-010-9529-y

14. WHO technical guidance. Clinical management of severe acute respiratory infections when novel coronavirus is suspected: What to do and what not to do. 11 February 2013. Available from: http://www.who.int/csr/disease/ coronavirus infections/InterimGuidance ClinicalManagement NovelCoronavirus_11Feb13u.pdf?ua=1

15. Note from the editors: MERS-CoV - the quest for the reservoir continues. Euro Surveill. 2013;18(50): $\mathrm{pii}=20663$.

16. Penttinen PM, Kaasik-Aaslav K, Friaux A, Donachie A, Sudre B, Amato-Gauci AJ, Memish ZA, Coulombier D. Taking stock of the first 133 MERS coronavirus cases globally - Is the epidemic changing? . Euro Surveill. 2013;18(39):pii=20596.

17. Eurosurveillance editorial team. Note from the editors: A new virus bringing back memories from the past. Euro Surveill. 2012;17(39): pii=20284.
18. WHO Guidance for the Use of Annex 2 of the INTERNATIONAL HEALTH REGULATIONS (2005). WHO/HSE/IHR/2010.4. Available from: http://www.who.int/ihr/revised_annex2_guidance. pdf?ua $=1$ 